\title{
Thermodynamic Solar Water Pump with Multifunction and Uses
}

\author{
Romdhane Ben Slama* \\ Department of Electromecanique, University of Gabes, ISSAT, Gabes 6029, Gabes, Tunisia
}

\begin{abstract}
The solar pump, object of the present study, is of a thermodynamic type, which is attached for the rural population of the country. The design of the pump is to lead to a reliable system of solar pumping, without maintenance and being expensive. It proceeds by suction tanks to the vacuum, created by vapour condensation inside the pump. Thus, this pump plays triple role of solar collector, pump housing and water tank. The daily quantity of pumped water reached $221 \%$ of the volume of the pump. The rate of filling reached $82 \%$ and the pressure drop is of 0.96 bar. Moreover, pumped water is naturally heated in the pump housing, which confers on this pump a second function of solar water heater. This double usage can be interesting in the places where it is necessary to draw water before heating it. This case occurs in areas where the rainwater is collected in large cisterns underground. The solar pump which proceeds by suction (discharge head lower than $8 \mathrm{~m}$ ) then finds an adequate application including its double function.
\end{abstract}

Keywords: Water pumping, solar energy, suction, thermodynamics.

\section{INTRODUCTION}

The problem of water is crucial in hot countries, and tends to be generalized in other areas struck by dryness. How to reverse the tendency of the sun effect: from dryness to development. The pump is intended to be reliable and inexpensive [1]. It is what we carried out by various prototypes from 10 to 500 liters [1,2]. Since it is a thermodynamic pump, the evaporation of water should be done at the highest temperature (near to $100{ }^{\circ} \mathrm{C}$ ), thus, we were brought to use reflectors to the four side of the flattened shape of the pump. A patent is deposited at the National Institute of Normalisation and the Patent Rights INNORPI of Tunis under number 15972 (SN 88014) [3].

\section{BIBLIOGRAPHICAL STUDY}

The literature comprises certain number of publications on the thermodynamic solar water pumps, operative by delivery [4-11]. This delivery is generated by the pressure of a working fluid (pentane or ether) heated in a solar collector (Fig. 1). The number of cycles that a pump can perform in a day is determined by the time taken by vapourization first and then by condensation. The temperatures are 50 to $80{ }^{\circ} \mathrm{C}$ and 5 to $15^{\circ} \mathrm{C}$ respectively. The lift is from 2 to $10 \mathrm{~m}$.

Although the pump efficiency is low (about $0.1 \%$ ), its main advantage is the absence of moving parts, and its relative simplicity gives ease of manufacture, maintenance, reliability, and low cost.

The principle of our adjusted pump rests, on the contrary, on pumping by sucking up. It uses the vacuum created by the steam condensation initially, in liquid state, in a closed container.

A first engineering design was carried out in Master's dissertation [1], where three prototypes of checking of the principle were carried out:

*Address correspondence to this author at the Department of Electromecanique, University of Gabes, ISSAT, Gabes 6029, Gabes, Tunisia; E-mail: benslama_romdhane@yahoo.fr a-

Electric water-heater of recovery: used to check the manufacture of the vacuum. Little water is left in the electric water-heater. By starting it, water evaporates, at $100{ }^{\circ} \mathrm{C}$, we shut off the current. A slow cooling creates the condensation of the steam and thus, the vacuum is created up to $76 \mathrm{~cm}$ of mercury.

b- A second prototype, with the same principle as the precedent, is no longer heated by electric resistance but by radiation, resulting from an artificial light (Fig. $\mathbf{2 a}, \mathbf{b})$. A vacuum is also reached in spite of the low sealing due to the closing of the container by a bolted pane.

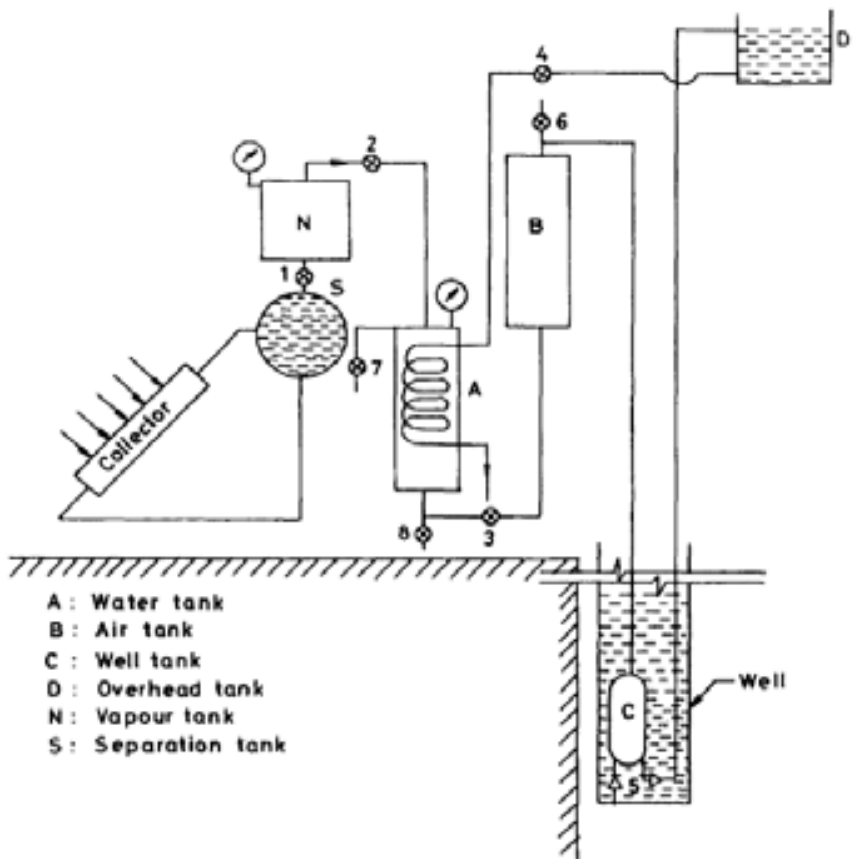

Fig. (1). Diagram of the Sumathy pumping system [5]. 
(a)

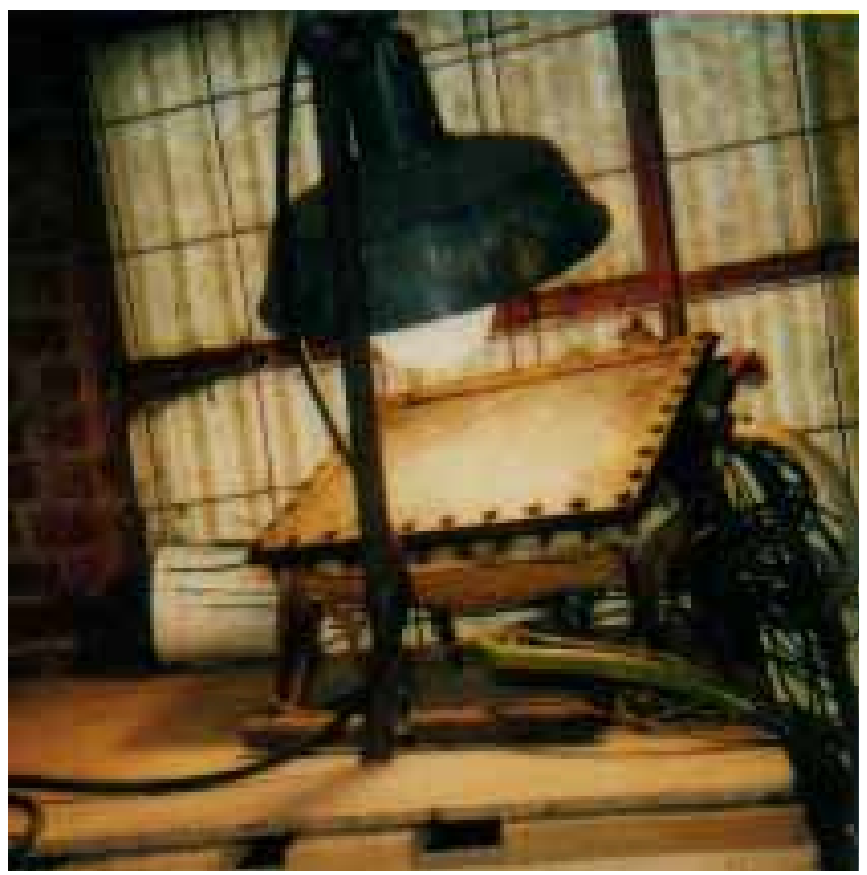

(b)

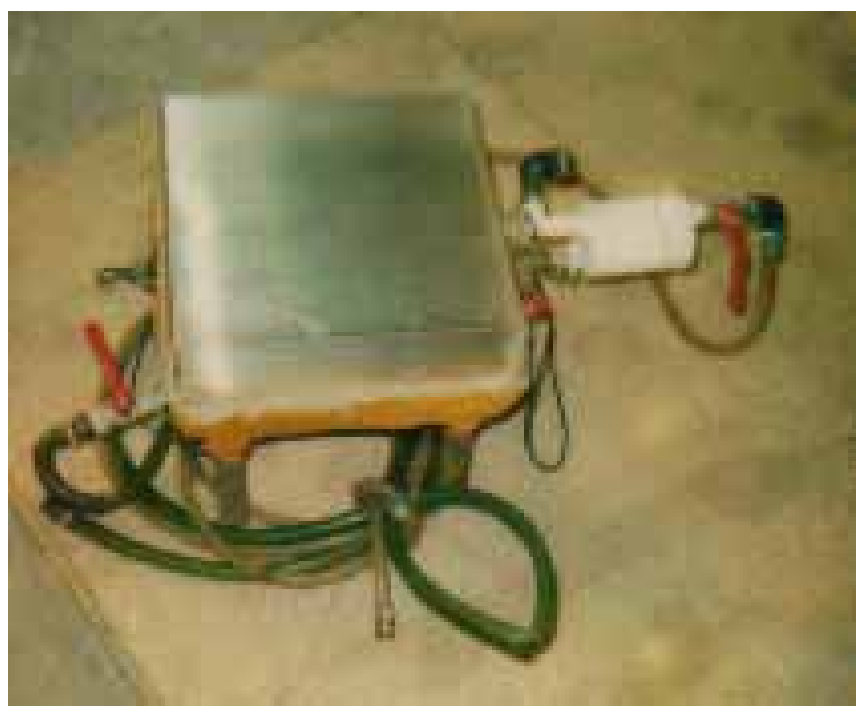

Fig. (2). Preliminary Prototypes of tests. (a) Illumination. (b) Daylight and cooling system. (c) The third prototype of principle checking, which will be taken as a model for a larger one (of 500 liters), uses sunlight and consists of a closed container admitting a glass cover to make the greenhouse effect. An additional cooling system was used to increase cooling. This system (Figs. 2b, $\mathbf{3}$ and 4) consists of circulation of water, directly inside the pump or inside an exchanger to start the vapour condensation and consequently create a vacuum.

Thus, several pumping cycles per day were completed. The valves were manually operated for the moment.

\section{THERMODYNAMIC SOLAR PUMP}

An other prototype has been realised in $\mathrm{PhD}$ dissertation, as represented in Fig. (3). Water evaporation was obtained due to solar energy. The cistern plays triple role of solar collector, pump housing and water tank. Moreover, this pump, by its principle of operation, automatically heats pumped water beforehand. The current evolution is used according to its capacities i.e. to pump water out of the cistern (a buried reserve within masonry, which recuperates rainwater) and then to heat it instantaneously.

A photograph of the pump, is shown in Fig. (4). Some reflectors have been added to increase the tempreture (Fig. 5).

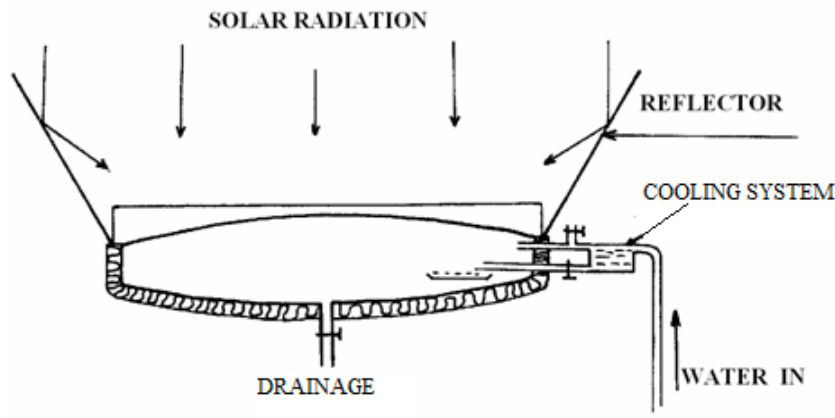

Fig. (3). General diagram of the thermodynamic pump by suction.

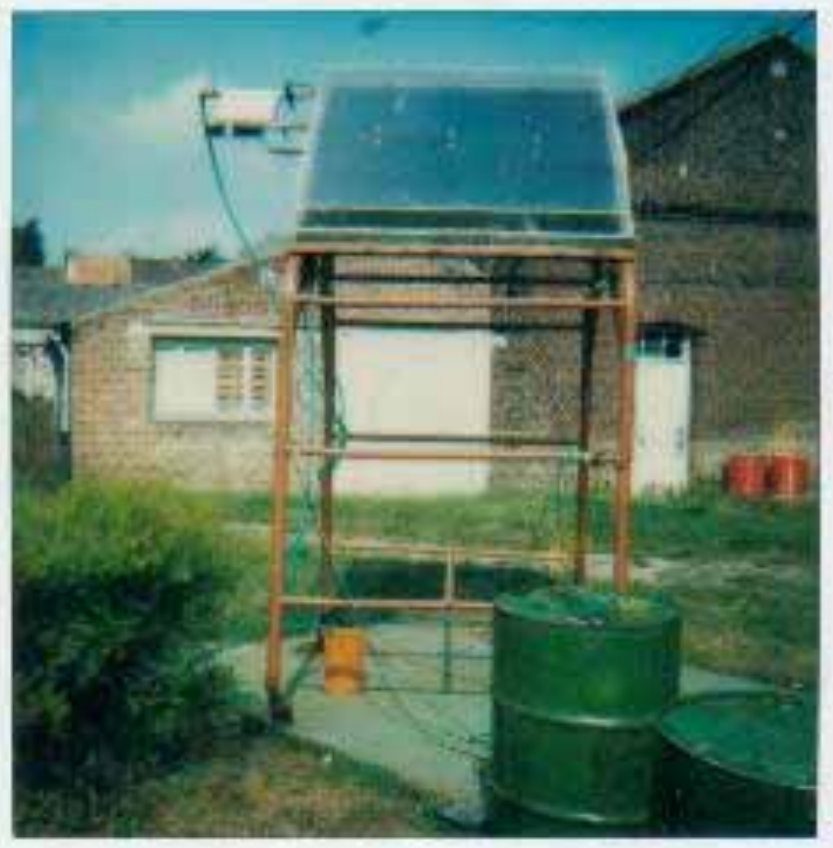

Fig. (4). Pump housing with the cooling reserve.

\subsection{Cycle of the Pump}

The pumping system presented in this article is not a continuous system and it can only pump intermittently.

The thermodynamic solar water pump can be regarded as an engine, whose cycle is represented in the diagram P-Vs (Fig. 6).

During heating, two different manners can be followed before carrying out cooling and pumping: to maintain the pump housing closed (would be only by lapse of memory to open the valve of setting to free air) or on the contrary to allow its setting the air free. However, the fact of maintaining the pump housing open during the heating (way $A B^{\prime}$ instead of $A B$ followed by $B B^{\prime}$ ) makes it possible to 
reduce the energy necessary for the heating and thus to increase energetic efficiency.

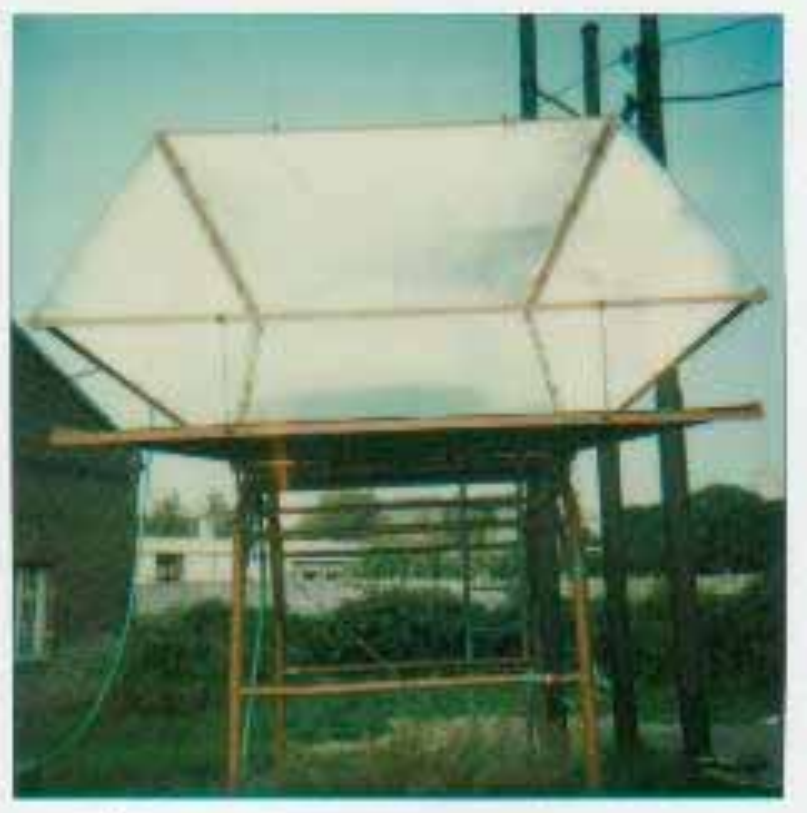

Fig. (5). the pump with its reflectors.

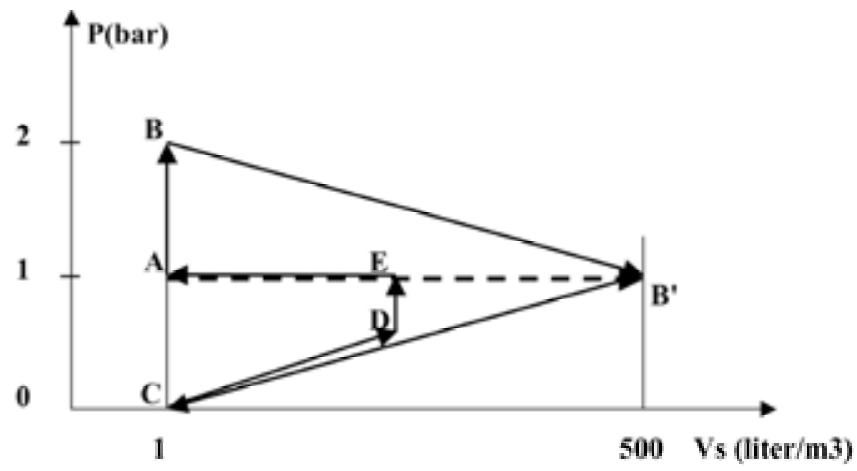

Fig. (6). Thermodynamic pump cycle.

AB: heating, pump closed.

$\mathrm{BB}^{\prime}$ : expansion at the end of the heating.

$A B$ ': heating, pump open.

B'C: cooling, creation of vacuum.

$\mathrm{CD}$ : pumping by sucking up.

DE: setting free of the air.

EA: water drainage.

Note: If pumped water is maintained in the pump housing, it heats. This fact could confer this pump to a second function, as a solar water heater, likely interested to some specific users.

This study has made it possible to show the influence of heating and cooling temperatures on the values of the vacuum. As for the rate of filling, it also depends on the total head of pumping.

\section{EXPERIMENTAL AND THEORETICAL RESULTS}

\subsection{Formal Error Analysis}

For the computations, here we only presented the equations 1 to 4 to calculate the filling rate, according to the total head and pressure drop variables. As it is a simple calculation, we have limited potential errors. We have no resolution of equations to make, nor any search for convergence.

On the other hand, for the experimental part of the study, there exist inevitable errors of measurement which we add in the new text.

Water and ambient temperatures are measured by a fercanstentan thermocouple; with a more or less $0.2 \%$ precision. The temperatures of reference points were checked and confirmed by mercury column glass thermometers, graduated to $2 / 10$.

The pressure drop reached by the tank during water vapour condensation is measured by a manometer probe, with a more or less 0.05 bar precision

The incidental solar radiation on the tilted plane of the collector is measured by a Kip \& Zonen Pyranometer. The relative error measurement is about $\pm 2 \%$.

The quantity of pumped water is measured by glass instruments graduated every $10 \mathrm{cl}$.

All these sensors are related to a Philips Transokomb Plotter.

For a pumping cycle, one measures the temperature reached during heating right before starting spontaneous cooling, and thus creation of the vacuum, following water drainage when the suction of water starts. At the end of pumping, one carries out the draining of pumped water, warmed in occurrence. This quantity of water is measured and recorded. The total head is measured at the end of the pumping between the higher levels of water contained in the tank of pumping and the pump housing. The room temperature is measured in the shade.

\subsection{Pressure Drop Reached-Water Velocity}

Pressure drop reached (Fig. 7) according to the variation in temperature between the heating and cooling: from the taken measurements, two curves have drawn corresponding to the cooling temperatures of 20 and $27{ }^{\circ} \mathrm{C}$. These curves show that the pressure drop is all the higher as the temperature of heating is closer to $100{ }^{\circ} \mathrm{C}$ and that the temperature of cooling is lower.

It is noticed that the curves have an exponential form and that the pressure drop is worth a bar for heating temperature of $110^{\circ} \mathrm{C}$ and with a cooling temperature of $20^{\circ} \mathrm{C}$.

$\mathrm{Dp}=$ Pat $-($ Pas + Pvs $)$ at TR

The velocity of water depending on the pressure drop reached and the total head of water [2].

$V 2=\sqrt{(D p-\rho . g \cdot H) \cdot 2 / \rho}$ 


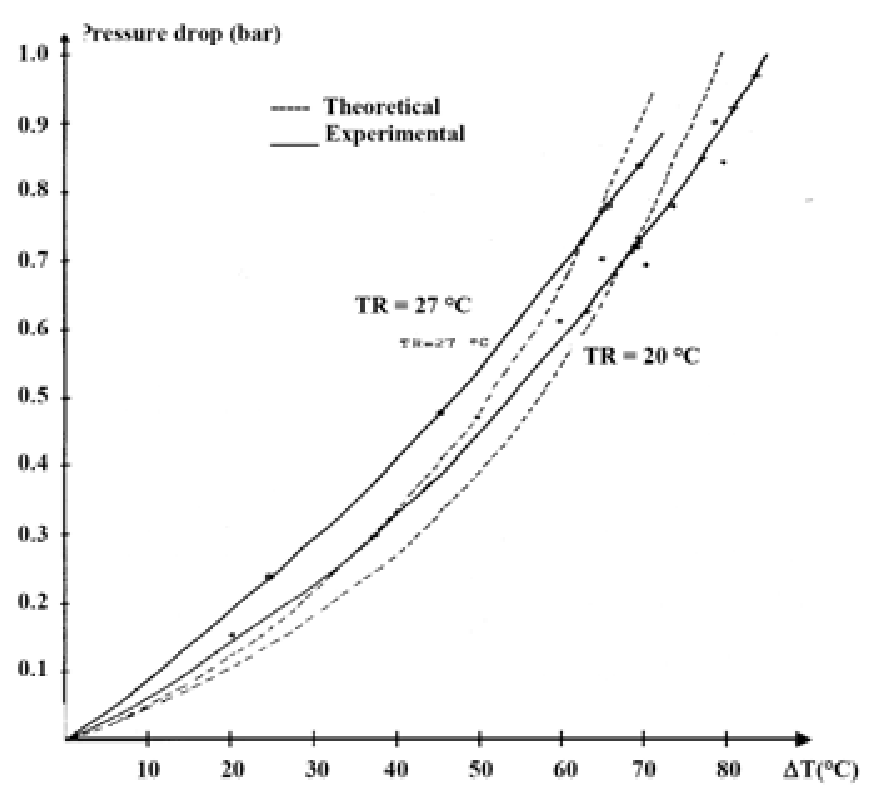

Fig. (7). Pressure drop reached according to the variation in temperature between the heating and cooling.

\subsection{Percentage of the Volume of Pumped Water}

* Percentage of the volume of water pumped according to the total head and of the pressure drop reached is given by the equation [2]:

$V p=V .\left(1-\frac{P a t-D p}{P a t-\rho \cdot g . H}\right)$ Then,

$\% V=1-\frac{(P a s+P v s) a t T R)}{P a t-\rho . g . H}$

Fig. (8) shows the importance of the pressure drop reached. Indeed, it occurs when the level of vacuum is high; the filling rate becomes important and independent of the total head, which is not the case of weak and average pressure drop.

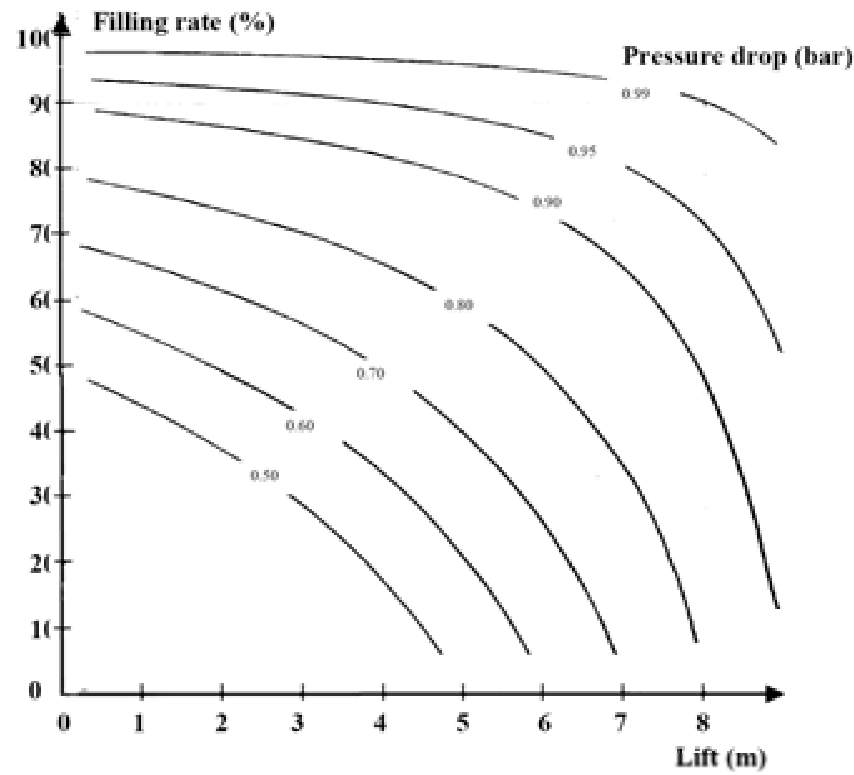

Fig. (8). Filling rate according to the total head and the prssure drop reached.
* Percentage of the volume of water pumped according to the cooling temperature at the end of the pumping:

The lower is the cooling temperature is, the more is increase in volume the percentage of the pumped water. The graphs give both the cooling temperature from which pumping $(\% \mathrm{~V}=0)$ starts, for total head and temperatures of cooling given (Fig. 9). These results have guided us to the need for a cooling system.

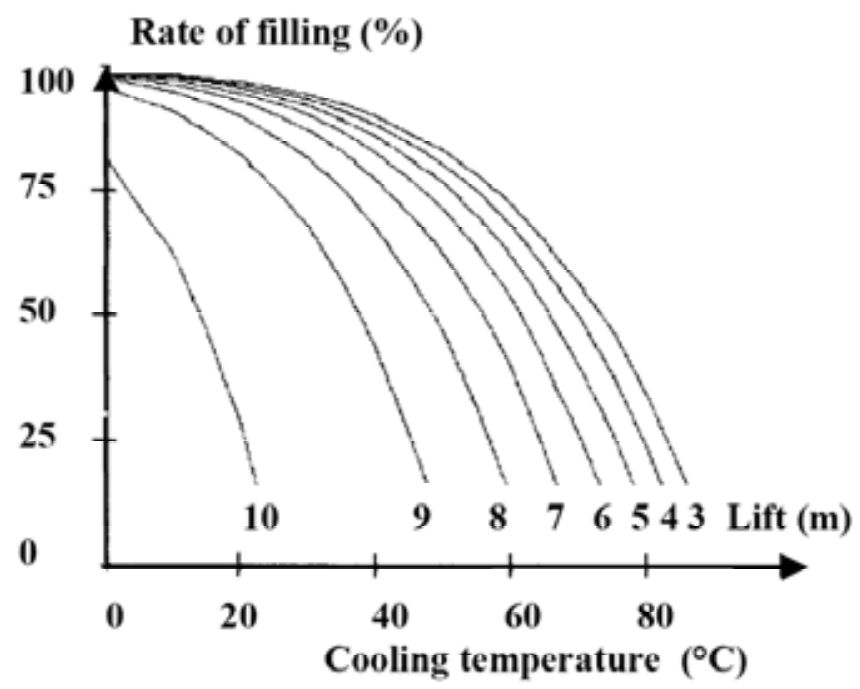

Fig. (9). Filing rate according to the cooling temperature and for various total heads.

*Percentage of filling according to the heating temperature (Fig. 10): The two curves, theoretical and experimental, are close, especially for heating temperatures in the neighbourhoods of $87^{\circ} \mathrm{C}$. The filling percentage is proportional to the heating temperature. The maximum rate of filling reached $80 \%$, which can also be Accounted By the pressure drop on the level of the connections.

Rate of filling $(\%)$

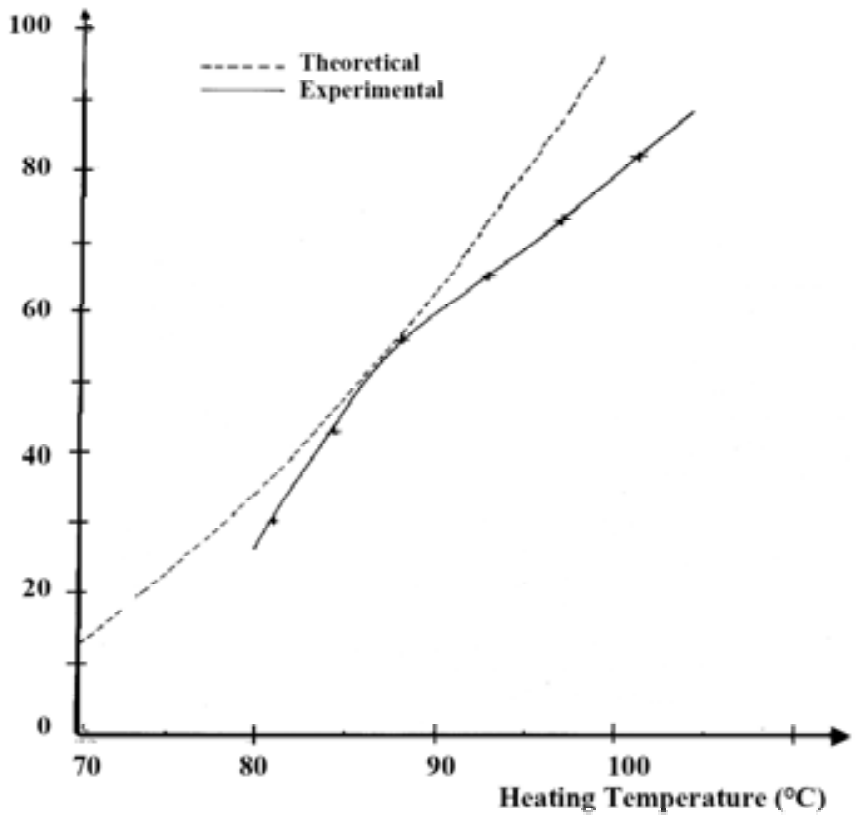

Fig. (10). Theoretical and experimental filling rate according to the heating temperature. 


\subsection{Daily Water Pumping Cycles}

Number of pumping cycles per day: Following the introduction of additional cooling devices system. The duration of process has considerably decreased, thus allowing to carry out several pumping cycles per day (Fig. 11). Each cycle is obviously in conformity with the diagram of Fig. (6) including the heating (rising curve), cooling (downward curve), pumping by aspiration, and draining (interval between two cycles).

The pumped water percentage for the four cycles are $73 \%, 62 \%, 59 \%$ and $27 \%$ respectively, that is to say on the whole $221 \%$ of the volume of the pump. Thus, quantity of pumped water depends on the volume of the pump.

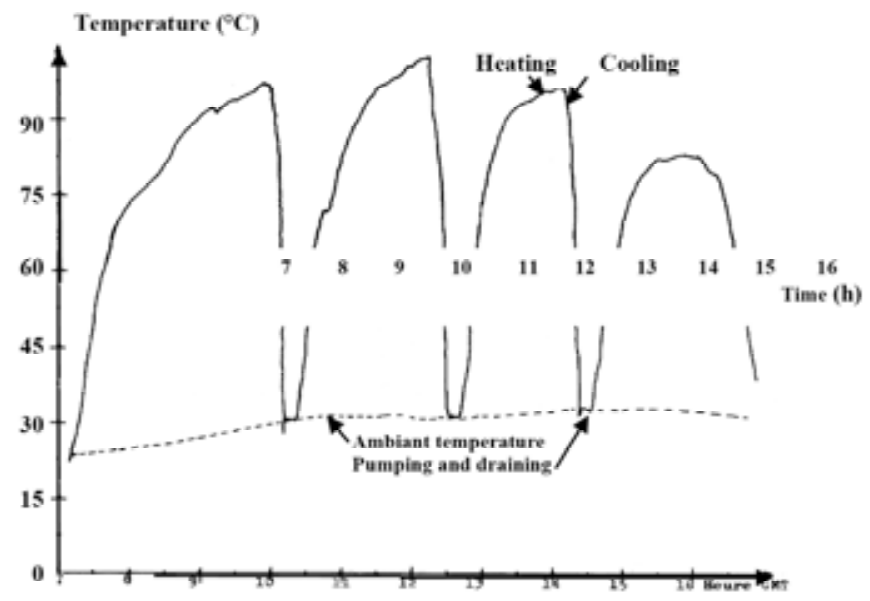

Fig. (11). Pumping cycles per day. On the July 8, 1984.

This pump, by its operation principle, automatically heats beforehand pumped water.

The current evolution is to use it according to its capacities i.e. to pump the water of cistern (reserve in masonry, buried, which recovers rainwater) and then to heat it instantaneously; which reflects the traditions of use, particularly of the south of Tunisia using rainwater for the baths.

\section{CONCLUDING REMARKS}

The manufacture of the vacuum necessary to pump, by suction tanks, solar energy was successfully carried out and made it possible to ensure the pumping of water. The operations of solar energy collect on water evaporation; vacuum manufacture, pumping and storage of water are made in the same element, that is qualified by multipurpose. It can also be used for multi uses: water pumping, water heating, hot air humidification etc.

If the pumped water flow is low, the same for the total head, this pump can be developed in the future according to its real capacities observed, i.e. pumped water with low discharge head by suction then to be heated, like that was observed in thesis [2]; what the other pumps, quoted in bibliography, cannot ensure them. Thus, this pump is distinguished from others by its capacity and faculty to heat water.
The climatic, energy and social conditions in the South of Tunisia enable us to predict that this could have a role to play in the future. Indeed in the south of the country, so many houses are fitted with water cisterns dug in the ground for the collection of rainwater, which is usually used for drinking, cooking, and washing, but also for the showers. The pumping out of this water is usually done manually (use of a cord and a bucket), because the flow is weak and the depth too.

Thus, this solar pump can fulfil its functions very well. The sun, evaporate water, to create the vacuum and to aspire it, then to heat it with the manner of a solar-water heater, whose storage is integrated here. The cycle can start again several times per day. If desired water is rather cold, the pump must be drained immediately after filling (partial).

Thus, we will see one in the South of Tunisia, for example, each water cistern with its integrated solar system of pumping and heating of water.

\section{NOMENCLATURE}

$$
\begin{aligned}
& \mathrm{Dp}=\text { Pressure drop }(\mathrm{Pa}) \\
& \mathrm{H} \quad=\text { Total head between water of well and pump (m) } \\
& \mathrm{P} \quad=\text { Absolute pressure (bar) } \\
& \text { Pas }=\text { Dry air pressure }(\mathrm{Pa}) \\
& \mathrm{Pa}=\text { Atmospheric pressure }(\mathrm{Pa}) \\
& \text { Pv.s = Saturated vapour pressure }(\mathrm{Pa}) \\
& \mathrm{TR}=\text { Cooling temperature }(\mathrm{K}) \\
& \mathrm{V}=\text { Space for air and vapour in the cistern (l) } \\
& \mathrm{V} 2=\text { Water velocity }(\mathrm{m} / \mathrm{s}) \\
& \mathrm{Vs}=\text { Specific volume (liter } / \mathrm{kg}) \\
& \rho=\text { Water mass density }\left(\mathrm{kg} / \mathrm{m}^{3}\right)
\end{aligned}
$$

\section{REFERENCES}

[1] Ben Slama, R. For a Reliable and Inexpensive Solar Pump Master's dissertation of energetic. University of Valenciennes, France, June, 1983.

[2] Ben Slama, R. Contribution to the Study and the Development of Pumps and Solar Collectors. Energetic Speciality Thesis. University of Valenciennes, France, May 20, 1987.

[3] Ben Slama, R. Patents $\mathrm{N}^{\circ} 15972$ (SN 88014) Solar tank with multifunction and uses National Institute of Normalisation and the Patent Rights, INNORPI, Tunis, March 23, 1990.

[4] A1-Haddad, A. A; Enaya, E; Fahim, M. A. Thermodynnamic Analysis of a solar thermal Water Pump. Appl. Therm. Eng., 1996, 16, 321-334

[5] Sumathy, K; Venkatesh, A.; Sriramulu, V. Thermodynamic analysis of a solar thermal water pump. Energy, 1996, 57,155-161.

[6] Sumathy, K. Experimental studies on a solar thermal water pump. Appl. Therm. Eng., 1999, 19, 449-459.

[7] Wong, Y.W.; Sumathy, K. Performance of a solar water pump with n-pentane and ethyl ether as working fluids. Energy Conversions. Manag., 2000, 41, 915-927.

[8] Wong, Y.W.; Sumathy, K. Performance of a solar water pump with ethyl ether as working fluid. Renewable Energy, 2001, 22, 389-394. 
[9] Wong, Y.W.; Sumathy, K. Thermodynamic analysis and optimization of a solar thermal water pump. Appl. Therm. Eng., 2001, 21, 613627.

[10] Wong, Y.W.; Sumathy, K. Solar thermal water pumping systems: a review. Renewable Sustain. Energy Rev., 1999, 3, 185-217.
[11] Roonprasang, N.; Namprakai, P.; Pratinthong, N. Experimental studies of a new solar water heater system using a solar water pump. Energy, 2008, 33, 639-646.

(c) Romdhane Ben Slama; Licensee Bentham Open.

This is an open access article licensed under the terms of the Creative Commons Attribution Non-Commercial License (http://creativecommons.org/licenses/by$\mathrm{nc} / 3.0 /$ ) which permits unrestricted, non-commercial use, distribution and reproduction in any medium, provided the work is properly cited. 